\title{
Understanding and preventing situations of abuse in health care: Navigation work in a Swedish palliative care setting
}

J elmer Brüggemann, Alma Persson and Barbro Wijma

The self-archived postprint version of this journal article is available at Linköping University Institutional Repository (DiVA):

http:// urn.kb.se/ resolve?urn=urn:nbn:se:liu:diva- 153753

N.B.: When citing this work, cite the original publication.

Brüggemann, J., Persson, A., Wijma, B., (2019), Understanding and preventing situations of abuse in health care: Navigation work in a Swedish palliative care setting, Social Science and Medicine, 222, 52-58. https:// doi.org/ 10.1016/j.socscimed.2018.12.035

Original publication available at:

https://doi.org/ 10.1016/j.socscimed.2018.12.035

Copyright: Elsevier

http:// www.elsevier.com/

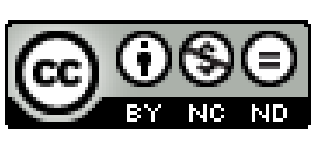




\section{Understanding and preventing situations of abuse in health care - Navigation work in a Swedish palliative care setting}

Jelmer Brüggemann ${ }^{\mathrm{a}, \mathrm{c}}$, Alma Persson ${ }^{\mathrm{b}, \mathrm{c}}$ \& Barbro Wijma ${ }^{\mathrm{c}}$

${ }^{a}$ Department of Thematic Studies - Technology and Social Change, Linköping University, Linköping, Sweden

${ }^{\mathrm{b}}$ Department of Thematic Studies - Gender Studies, Linköping University, Linköping, Sweden

${ }^{c}$ Department of Clinical and Experimental Medicine - Gender and Medicine, Linköping University, Linköping, Sweden

Contact details corresponding author

Jelmer Brüggemann, Department of Thematic Studies - Technology and Social Change, Linköping University, 58183 Linköping, Sweden. Tel: +46 132829 58. Email: jelmer.bruggemann@liu.se

Email addresses of co-authors

Alma Persson: alma.persson@liu.se

BarbroWijma: barbro.wijma@liu.se 


\section{Abstract}

In their everyday work, health professionals find themselves in situations that they perceive to be abusive to patients. Such situations can trigger feelings of shame and guilt, making efforts to address the problem among colleagues a challenge. This article analyzes how health professionals conceptualize abusive situations, and how they develop collective learning and explore preventive strategies. It is based on an interactive research collaboration with a hospice and palliative care clinic in Sweden during 2016-2017. The empirical material consists of group discussions and participant observations collected during interactive drama workshops for all clinic staff. Based on three types of challenges in the material, identified through thematic analysis, we establish the concept of navigation work to show how health professionals prevent or find ways out of challenging and potentially abusive situations. First, the navigation of care landscapes shows how staff navigate the different territories of the home and the ward, reflecting how spatial settings construct the scope of care and what professionals consider to be potentially abusive situations. Second, the negotiation of collective navigations addresses the professionals' shared efforts to protect patients through the use of physical and relational boundaries, or mediating disrupted relationships. Third, the navigation of tensions in care highlights professionals' strategies in the confined action space between coercing and neglecting patients who oppose necessary care procedures. Theoretically, the concept of navigation work draws upon work on care in practice, and sheds light on the particular kind of work care professionals do, and reflect on doing, in order to navigate the challenges of potentially abusive situations. By providing a perspective and shared vocabulary, the concept may also elicit ways in which this work can be verbalized, shared, and developed in clinical practice.

\section{Keywords}

Sweden; abuse in health care; navigation work; care practice; interactive research; qualitative study; forum play 


\section{Introduction}

During an interactive research collaboration with a hospice and palliative care clinic in Sweden, we followed healthcare professionals for a year and a half as they worked on developing their skills in understanding, dealing with and preventing abuse in health care. This article is based on the ethnographic material we collected and analyzes what is challenging to health professionals in situations they defined as abusive to patients, how they make sense of these challenges, and what they do in these situations. We introduce the concept of navigation work to describe the ways in which the care professionals are constantly in touch with the relational and contextual dimensions of clinical encounters, and how these dimensions are deployed and developed to find ways out of potentially abusive situations.

Abuse in health care has often been defined as procedures or interactions that patients experience as neglecting or dehumanizing (Brüggemann \& Swahnberg, 2013; d'Oliveira, Diniz, \& Schraiber, 2002; Jewkes, Abrahams, \& Mvo, 1998; Swahnberg, Thapar-Bjorkert, \& Bertero, 2007; Swahnberg, Wijma, Hearn, Thapar-Björkert, \& Berterö, 2009). Conceptually, abusive incidents in health care settings can embrace a large range of phenomena, including criminal offences such as rape and sexual assault (Disch \& Avery, 2001) or the slapping of patients (d'Oliveira et al., 2002). However, most of the literature related to abuse in health care focuses on the often unintentional and/or institutionalized transgressions of patients' integrity, autonomy or dignity - patients' perceived loss of their human value (Brüggemann, Wijma, \& Swahnberg, 2012). Patients have described such abusive experiences as feeling nullified, being mentally pinioned and losing a power struggle (Brüggemann \& Swahnberg, 2013; Swahnberg et al., 2007, Swahnberg et al., 2009). These kinds of abusive experiences in care settings have been described in the literature in various other terms as well. Coyle (1999) labelled similar incidents as personal identity threats, emphasizing the aspect of dehumanization in patient narratives. This also relates to what Halldorsdottir (1996) called uncaring encounters, where patients experience a care professional as careless, ranging from being disinterested to being inhumane. Mol (2008) is not willing to pin down what good care consists of, but shares the notion that care is bad when 
patients are neglected, when no-one listens, or when parameters, rather than suffering human beings, are cared for. It is these kinds of dehumanizing, neglectful encounters, and how care professionals perceived of them, that were central to this research project.

Dehumanization is not only an important theme in qualitative "insider" studies based on the experience of patients; there is a long tradition within medical sociology that, from an "outside" view - on behalf of patients - problematizes the ways in which medicine and health care providers dehumanize patients through processes of objectification of their bodies (Timmermans \& Almeling, 2009). Some have argued that objectification need not be problematic per se, but rather depends on how the stakeholders give meaning to particular health care outcomes and interactions (Cussins, 1996; Timmermans \& Almeling, 2009), forcing the "outside" view to stay close to what "insiders" do and value. Given that such interactions are shaped by local rules and values, what is seen as dehumanizing and abusive to patients - of course - differs greatly between cultures, setting, and time periods. In the same way, care professionals also have very different ideas of what constitutes abusive situations, and how they can be avoided or counteracted. Following this position, in our interactions with professionals at the clinic, we did not pinpoint what counts as abusive treatment or not, but adopted an open, practiceoriented approach. We described abuse in health care (kränkningar in Swedish) as situations that staff identify as abusive to their patients (in line with Zbikowski, 2014), further contextualized by giving examples and themes from earlier patient interview studies (Brüggemann \& Swahnberg, 2013; Swahnberg et al., 2007; Swahnberg et al., 2009).

Little is known about how care professionals make sense of and tackle situations they perceive as abusive to patients. One study showed that care professionals understand patients' experience of abuse as sometimes being part of their professional responsibilities, but at other times falling outside of it and not being something that demands action from the professional (Swahnberg, Zbikowski, \& Wijma, 2010). An example mentioned in the study is how staff members in interviews tended to place patients' experiences of abuse outside of their professional responsibilities because they themselves also felt abused. Yet another study examined staff's awareness of abuse in health care 
and identified a relation with staff's contextual possibilities to act (Swahnberg \& Wijma, 2011), recognizing how the conditions of care frame the way in which care encounters are understood. Relevant work is also found in the caring sciences, in particular studies of nursing and the protection of patients' dignity. This work primarily aims to thematically develop insights into what affects patients' dignity (Lin, Watson, \& Tsai, 2013) and the different aspects of patients' dignity that nurses identify as important to maintain (Lin \& Tsai, 2011). The studies referred to in this subsection cover ways in which abuse in health care or violations of patient dignity is made sense of by professionals, but call for more in-depth explorations of these understandings and what they mean in practice. Therefore, the current study aims to analyze the conceptualizations, skills and tricks that care professionals use and develop in order to prevent and deal with situations they perceive as abusive to patients. We also aim to spell out how such analyses can be of relevance to clinical and theoretical discussions on challenges in everyday care.

We frame this article against the backdrop of an emerging field of research on care that draws upon medical sociology and anthropology, and science and technology studies, emphasizing the relational and material dimensions of care practices (Cussins, 1996; Mol, 2008; Mol, Moser, \& Pols, 2015). We do so by establishing the concept of navigation work that serves to make sense of the ways in which care professionals are in touch with diverse contextual dimensions of care encounters. Navigation work also serves to describe how these dimensions are deployed, individually and collectively, to find constructive ways out of challenging, potentially abusive situations, and to prevent such situations from occurring. We think of navigation work as a concept for capturing not only clearly visible work in care encounters but also less visible work (Star \& Strauss, 1999). It touches upon the concrete and hands-on tinkering with relational and material aspects in clinical encounters (Mol et al., 2015) as well as the collective, backstage (Goffman, 1959) monitoring and shaping of care landscapes in which these encounters take place. As part of this, navigation work relates to what Pols (2006) labelled contextual reflexivity, a particular type of explorative individual or collective articulations of everyday situations, in which "[t]he good as well as the more doubtful situations can be analyzed as a 
consequence of specific patterns of traditions, values, knowledge, and routines used" (2006, p. 227). After describing our research methods below, we explore navigation work through three types of challenges that recurred during our interactions and workshops with the care professionals.

\section{Research design, methods, and material}

Previous work in the area (Brüggemann \& Persson, 2016; Wijma, Zbikowski, \& Brüggemann, 2016; Zbikowski, 2014) has been organized as traditional intervention studies, while the current project built on interactive research (Svensson, Ellström, \& Brulin, 2007). This approach has been developed in the Nordic region and is related to action research, with researchers directly intervening in practices and engaging in change activities (Svensson et al., 2007). An open and joint approach invited the clinic to shape the project in a way that made sense and was valuable to their work, while it allowed us to guide and analyze relevant processes in an ethnographic manner. This interactive approach allowed us to produce analyses related to the topic of change, in a way similar to how Zuiderent-Jerak (2015) describes situated interventions.

Upon presentation of the planned project at a seminar, we were approached by a representative of a south-Swedish hospice and palliative care clinic who expressed an interest in forming a collaboration, later confirmed in dialogue with the clinic management. The analysis presented here is the result of this $1 \frac{1}{2}$ year collaboration in which our interdisciplinary research team and the clinic have organized work against abuse in health care. The main task of the clinic is to provide palliative care, which it provides in patients' homes and on a small ward. Care on the ward and care in the home are two distinct parts within the organization of the clinic, and staff generally work in one of these two units. The staff that provide palliative care at patients' homes also deliver advanced home health care services that go beyond what is provided by regular homecare assistance - a group of practitioners staff meet regularly in their work in patients' homes. The majority of the sixty employees at the clinic are nurses and auxiliary nurses; others include several physicians, secretaries, a physiotherapist, and a dietician. 
The interactive project consisted of three stages, and we collected empirical material from group discussions and notes from participant observations during each stage. Stage 1 (spring 2016) was an explorative stage during which we organized several group discussion sessions about abuse in health care for the clinic staff. We also gave short presentations of our previous experiences working with abuse in health care. Stage 2 (fall 2016) was the training stage. The central activities in this stage were four full-day workshops. All members of staff at the clinic were assigned to one of the four workshops, all led by the same professional drama instructor and following the same overall structure. Each group consisted of approx. 15 staff members from both home-care and the ward-team, including nurses, physicians, administrators and managers so that there was a mix of professions and clinical expertise in each group. The workshops were based on forum play, a model that uses drama pedagogy as a method to enable staff to train together to deal more adequately with situations that they have identified as abusive to patients (Josephson, 2011; Wijma et al., 2016). Forum play is a Swedish version (Österlind, 2011) of Augusto Boal's Forum Theatre (Boal, 2000), that combines exercises that explore values with interactive role-playing. The initial component of all workshops involved all participants describing a situation that they had experienced or heard about and which they considered to be abusive to a patient or, particular to this clinic, a patient's relative. After a few warm-up drama exercises, the participants selected three of the described situations to work with through voting. Here we saw a tendency among the professionals to vote for situations they considered relevant to patients, and where the keys to how the situation could be "solved" or prevented were not very obvious. They then chose one of these situations, forming three smaller groups, and transformed the described situations into a more generic and less personal scene that could be performed for the rest of the participants in the workshop. The scenes always ended in a dilemma in which the risk of abuse peeked, after which the other participants were invited to test "solutions" - to find ways out of the challenging situation. Stage 3 (spring 2017) was an anchoring stage, aimed at finding ways to transfer what had been learned during the earlier stages into clinical work and routines. Stage 3 involved meeting with the clinic management and a larger work place meeting, during which the staff reflected in smaller groups on the forum play 
sessions. They also worked individually and in small groups with questions of what the management, their team, and the staff themselves could do in order to implement and develop their work against abuse in health care. These reflections were summarized in an overview that was passed on to the head of the clinic and constituted the symbolic end-point of the collaboration.

After the decision taken by the management to join the collaboration and concluding that the project did not require ethics approval according to Swedish law, the clinic staff were informed about the project. We presented its interactive and open approach, our role as researchers, and the time frame. The educational part of the project was organized as an employee-training program, administered by the clinic and held during working hours. All staff members were assigned to one of four workshops and expected and encouraged to participate by the clinic management, whom also themselves participated. Nearly all staff joined a workshop. During the workshops, the instructor invited participants to engage, but active participation was voluntary.

The research design and forms of data collection were outlined by the research group and approved by the clinic management, and the staff were informed about our presence, our methods, and (for group discussions) any audio recordings made. The collected material was analyzed by thematic analysis (Braun \& Clarke, 2006). In a first stage, JB and AP individually conducted an initial coding of all group discussions and field notes from the workshops. In a second stage, these codes were clustered into larger themes against a backdrop of the study's theoretical approach. In a final stage, we developed navigation work as an analytical concept. All authors contributed to refining the way in which navigation work informed and was informed by the analytical themes.

Before we turn to the analysis, a few notes about the context. Palliative care, or care at the end of life (Fürst, 2000), differs from many other care settings in ways that are relevant for the current analysis. First, palliative care is not directed towards health but rather towards non-suffering and dying with dignity, as it is practiced in Sweden. This creates ideas about patient needs, reasonable interventions, and long-term considerations that differ from many other types of care. Second, a relatively large fraction of palliative care patients suffer from conditions that impair their decision- 
making ability. Examples are patients with dementia and patients close to death, with very low levels of consciousness. Such patients may not always be able to express or act upon their will. Third, an important part of the palliative care philosophy is interdisciplinary teamwork. The way in which palliative care is organized in teams where responsibilities are shared is now used as a model for other care settings (Crawford \& Price, 2003). Working practices at the host clinic were heavily based on teamwork.

\section{Navigation work and three archetypical challenges}

In the analysis, we take a starting point in three scenes that represent archetypical challenges dilemmas that in various forms recurred in staff's accounts of potentially abusive situations. These three challenges highlight specific facets of navigation work that can improve understandings of how professionals together make sense of and work against abuse in health care.

\section{A chaotic visit - navigating care landscapes}

Steven and Sofia, a nurse and doctor, are on their way to check up on Anna, a patient with advanced chronic obstructive pulmonary disease. When they arrive at Anna's home, they are greeted by her neighbor who is paying her a visit. The neighbor appears to be very friendly with Anna and her partner, but he becomes increasingly intrusive during the course of the visit. When he starts joking about Anna's secret smoking habits, Anna seems very uncomfortable, and the neighbor obstructs Steven and Sofia in their work. Neither Steven nor Sofia know how to cope with the situation, and the visit becomes increasingly chaotic. (Forum play, stage 2)

This scene, acted out in one of the forum play workshops, concerns the ways in which care is shaped and conditioned in specific spatial settings, and how professionals navigate such landscapes differently. 
The relationships between caregivers and patients are usually defined at this clinic by the fact that work takes place in the homes of the patients, as well as in the more traditional care setting of the palliative hospital ward. These particularities change the professionals' understanding of what care is about and affects their understanding of their position as professionals, the position of the patients, and what may be considered abuse. This becomes clear in the different ways that relationships between staff, patients and family members are constructed. The following statement concerns care in the home.

In particular, I remember a husband with alcohol problems, who was really difficult to deal with. You never knew if he would be sober or drunk, but he was lying next to her, a really destructive relationship. But that's not our business, I mean, she was constantly abused, that patient, but it's not our business, or what should we do? (Group discussion, stage 1)

Others contrasted this to situations on the ward, where abusive relatives would be stopped and firmly reprimanded. Part of the navigation work carried out by professionals here involves finding the boundaries of what constitutes the care landscape and what falls outside of it. Anything that falls outside was considered a private matter. So, for this type of challenge, the professionals are not uncertain about the harmfulness or wrongfulness of a specific situation, but engage in negotiations about what is included in the practice of care - what falls within the responsibilities of the professionals, and what lies outside. The relationship to the patients, for example, differs between different locations.

First of all, we are in the patients' homes, which is different from how most other people in healthcare meet patients, who tend to regress in traditional care settings [...] where the power imbalance is very, very apparent. That imbalance is 
somewhat reduced when you actually take your shoes off after entering the patient's front door. (Group discussion, stage 1)

Taking off one's shoes, a Swedish custom when visiting someone's home, acknowledges that this encounter is taking place in the patient's home. This is a place that the patient owns, where she has her relationships and rules. The home, most argue, makes staff more aware of their way of being professional. Several of them describe a feeling of being more careful in the home environment, compared to how they act on their "home turf" on the ward. In one account, the ward is described as "more dangerous [...] because you feel like you kind of own the space". Taking off shoes may manifest a shift toward less hierarchical relationships, similar to the way in which putting on a white coat can be seen as doing the opposite (Wellbery \& Chan, 2014).

Although the professionals position themselves as more careful in home settings, they mention at the same time an increased risk of situations in which patients may feel abused. One member of staff described the home as a "minefield for abuse", because the professionals are in a sense not always guests, but sometimes intruders, occupying the patient's private sphere.

In the home, it's not just "Now I will give you a vaccination shot". I'm not saying it's easy [at the ward] but it's kind of an isolated event. But for us, it's everything from walking through the door with or without knocking, ringing the doorbell or not ringing the doorbell, having a door key or not having one, it's everything, every single act can either be a good or a bad thing, depending on the situation and the people, inside and outside that door. There are so many parameters, it's a minefield for abuse, really. (Group discussion, stage 1) 
This account articulates how homecare settings transform and extend the act of caring, in ways that mundane activities become incorporated into what comprises professional care or abuse. As homes differ more than hospital rooms and are owned by different patients, they also demand more work when navigating very distinctive care landscapes. This does not mean that this navigation work is more visible or more difficult than it is in other environments. Rather, it is a particular form of navigation work that emphasizes and takes into account the risks of certain kinds of abuse.

\section{A bare body - negotiating collective navigations}

Agda has a large and painful pressure sore on her lower back. While Maria, a nurse, and Emanuel, an auxiliary nurse, change the bandage, as they do every day, Agda has her naked backside turned towards the door to the corridor. She cannot see who enters or passes the room, but she can hear everything. At one point, physician John enters the room unannounced and is audibly shocked by the sore's appearance. Maria and Emanuel now stand with the physician, looking at and talking about Agda's pressure sore as if she wasn't present, making Agda feel increasingly uncomfortable, vulnerable and exposed. (Forum play, stage 2)

Versions of this situation were the ones most commonly engaged with in the forum play workshops. It illustrates clearly how the most mundane tasks, such as changing bandages on a patient's pressure sore, can put patients in situations that become abusive. Participants in some workshops perceived this situation as abusive in that the patient felt vulnerable and exposed because of the bare body. For example, staff described situations in which they entered the home of a patient when a nurse was in the middle of changing bandages but had left the room, and the more or less naked patient, to get a fresh bandage. In these cases, covering the naked parts of the patient's body solves the problem and nothing else needs to be discussed or dealt with further. 
This particular version of the situation does indeed illustrate an aspect of vulnerability, but raises other concerns as well. It becomes apparent here that the patient becomes nearly invisible when other professionals, whom she cannot see, enter the room and start discussing the body as an object Agda becomes little more than a pressure sore. In such situations, the navigation work that professionals displayed in the forum plays and discussions involved three main strategies: proactively working with door-signs, reactively establishing relational boundaries, and mediating the relationship between the other professional and the patient.

In the final group discussions, which took place six months after the forum play workshops, the staff described how they had developed new door signs to communicate with each other.

I walked around at the ward, thinking about how I do things, and tried to respect our signs a bit more, and use the signs we have. And we have developed a new sign, "Nursing care ongoing".[...] Because I often experienced that patients' relatives just entered the room, because it's theirs. As a relative, I need not respect "Do not disturb" when it's my relative, but "Nursing care ongoing" is more respected. (Group discussion, stage 3)

The new sign, "Nursing care ongoing", conveys a reason not to enter the room. Or, in situations in which someone must enter the room (to fetch necessary material, or when a phone call is pending), that person knows what is going on, and is aware of the need to be discrete and connect immediately with the colleagues and the patient in the room. In other words, the collective establishes clear boundaries to their care setting and inform each other's navigation work. The signs are also more than being informative markers in a complex care landscape: they are reifications (Wenger, 1998), material nodes that collect and mirror a collective learning process. The signs, irrespective of the words on them, may mobilize lessons learned, for example forum play experiences from this project, and thereby inform 
navigation work. But this, as the professionals recognize, requires a process of reminding each other to respect the signs, of seeing the signs and making them relevant to each other.

When a nurse and an auxiliary nurse try to create a safe space for their patient while they change bandages on the pressure sore, it is crucial to keep the number of people in the room to a minimum. When door signs are not present or are ignored, as happened to Agda with her pressure sore, one way to reactively establish boundaries around the patient is to ask the colleague to leave the room and come back when the procedure is finished. This may be straightforward, or it may be difficult, such as may be the case in a conflict with existing hierarchies. It became obvious in the workshops that navigation work is not only the reading and activation of surroundings, but also involves the hard work of being attentive to other stakes than the patient's needs. If there is a risk that denying a colleague access to a room will lead to conflict, the staff tended to deploy a less confrontational approach mediation.

Mediation, in various forms, was a common way of addressing this challenge, in which Agda becomes increasingly exposed, vulnerable, and anxious. As different versions of this scene developed in the workshops, the participants took turns experimenting with a range of actions. One of the first forms of mediation that they tried to use was verbal mediation. In the case of Agda, nurse Maria might say, "Agda, doctor John just joined us and he is going to take a look at your sore as well, are you okay with that?" This form of mediation then continues to work to create a dialogue in which Agda is included as an active part, establishing a relational connection between John and Agda. Other forms of inclusion than verbal ones were also used in the workshops. One common way of reducing the patient's feeling of being vulnerable or objectified was to form a physical alliance with them. When the person who assumed the role of Maria, the nurse, pulled up a chair to Agda's bedside, or knelt beside her bed close to her face, it substantially reshaped the relationships between patient, nurse and doctor. Establishing eye-contact and positioning themselves on the same level as the patient forms a visible connection that disrupts professional bonds and establishes a nurse-patient alliance that may diminish feelings of objectification, despite John's position in the room. 
It appears that mediating strategies are deployed when the nurse believes that establishing firmer boundaries (by such means as posting a "Nursing care ongoing" sign or asking a doctor to leave the room and come back later) is not going to work or will come at too high a price. Mediating strategies allow the nurse to protect the patient's integrity and avoid the risk of becoming a bystander to something they find unacceptable (Brüggemann, Forsberg, Colnerud, Wijma, \& Thornberg, 2018).

\section{A fear of needles - navigating tensions in care}

Miriam, a physician, makes a phone call to Peter, a nurse, on his home healthcare round in the region. Miriam tells Peter that she has received the test results of an elderly patient, Maya, and they show that she has an infection and needs antibiotics. Miriam emphasizes that Maya needs to start her treatment right away. Peter, who is accompanied by student nurse Lea, knows that Maya has a severe fear of needles, but also that they need to treat Maya quickly in order to visit other patients on schedule. Peter is worried, but Miriam tells him to take care of it right away. When Peter and Lea meet Maya, she refuses to have the injection. Peter shows signs of being under time pressure, and when his initial efforts to persuade Maya are not successful, he ends up asking Lea to hold Maya still for a moment, and get it over with. The injection follows. (Forum play, stage 2)

Although the participants regarded the scene they developed as slightly exaggerated, it captures a recurring clinical dilemma - a conflict between the patient's will and the professional's duty arising from their knowledge of what is best for the patient or from a legal obligation. As one auxiliary nurse expressed it: "What to do when a patient doesn't want to take a shower? If we go along with that, that's not right either" (Group discussion, stage 1). The will and duty to do what is best for the patient, which was a strong discourse at the clinic, paradoxically became one of the norms that created many challenges and tensions, with the risk of "crossing a line" into abusive situations. The ideal of always listening to the patients' will and being respectful to their choices was contrasted with the consequences 
of such action, which may be, for example, a loss of dignity (e.g. not being washed) or a risk to health (e.g. not receiving certain medical interventions).

I think we are a bit quick here sometimes, with homecare assistance, for example. Because we enter the home and say like "Think about an alarm now", "Get an alarm", then patients can get provoked and say "What do you mean 'alarm'? I can go to the bathroom myself, what are you talking about?" "Well, yes, but in three weeks you may not", and then they are provoked "What do you mean? Will there be people running around here when I have to go to the bathroom?". I think we should present this in a better way. (Group discussion, stage 1)

The professionals framed the challenge in this situation as how to inform a patient and any spouse or family about the importance and rationale of a certain medical intervention without the information being experienced as negative persuasion, still respecting the patient's right to choose. The staff emphasized that there is a bottom line concerning interventions, in particular in people's homes: "[T]here are rules also, it's not compulsory care. The patient always has the right to say what they want, by the law, and then we just need to give way [others agree]" (Group discussion, stage 1). This bottom line, however, was not helpful in many dilemmas: the duty and the desire to provide good care and do what is best for the patient were not easily set aside. On the contrary, the position of being responsible for a patient implied resilient navigation work, and the healthcare professionals identified a range of possible actions during the forum plays that would be constructive.

We see that professionals face a challenge and are caught between approximating neglect and exercising coercion. When working with this dilemma, they mobilize not only their knowledge of what is best for the patient but also the patient's own concerns. This enables them to find out how the patient's situation can be improved. As Mol (2008) emphasizes, it may not be important for the patient who decides what, but rather how her situation will improve, or, in Maya's case, how the 
situation is best managed, in light of her fear of needles and being terminally ill. How the professionals in our study tried to do exactly that can be understood in terms of what Driessen (2018) calls will-work, which emphasizes the relational dimensions of wanting. In this understanding, the will of a person is not seen as autonomous and static, but rather as something that comes into being in interactions. Similar to the techniques of motivational interviewing, this is working with a will that "does not figure as an available resource ready to tap into, instead it is performed as an outcome of the intervention" (Vogel, 2016, p. 329). An important difference between coercion and will-work, Driessen (2018) states, is the critical reflection on what really is good for the patient and to make the patient really want to get an alarm or take a shower. Lea can reasonably assume that Maya, on some level, wants the antibiotics, as she has sought care and taken blood tests. It is on this common ground that Lea tries to find ways within the seemingly constricted situation and navigates pathways to align the patient's will with her own will. In their efforts to find ways to work around tensions between two different values, doing good and respecting the patients' autonomy, the aspect of time was important. When time is scarce, the risk of abuse increases. Staff in several group discussions described that they were left in certain stressful situations with no choice but to override the will of the patients, in order to perform the necessary procedures on time. They described a sort of destructive auto pilot mode in which they were less able to use the resources that are otherwise available to them.

I think that it is about understanding what situations can be, you know, tense, and when I am aware of that I can choose to do the right thing. But in some cases, sometimes I will need to make the decision to sort of override, because of the situation, or time restrictions, or just feeling stuck. (Group discussion, stage 1)

The example of the patient who is afraid of needles was often solved by spending more time than scheduled - either by discussing the reasons for the injection in a calm way, or by taking the time to use an anesthetic patch and return some time later to do the injection. In the tense situation described 
above, allowing the procedure to take longer is one of the most important resources for preventing abuse.

\section{Discussion}

This article has analyzed how health professionals make sense of and work with challenging and potentially abusive situations for patients, conceptualized as professionals' navigation work. We conducted group interviews with health professionals at a palliative care clinic in Sweden about their practices, and organized drama workshops for them to explore work against abuse. We observed the professionals while participating in the drama workshops. In the material we collected, we thematically identified different ways in which staff work with everyday challenging situations. Navigation work describes how the professionals navigate through the particularities of care settings such as the patient's home; how they create boundaries and establish relational connections to protect patients' integrity; and how they align seemingly incompatible ends and demands.

Over the last decade, abuse in health care has been studied at a number of clinics in Sweden. Following staff who work in very different medical specialties has shown that experiences and challenges of abuse in health care are highly situated and local. At a women's clinic, the intimate examinations that render patients vulnerable are considered to be a particular challenge, while staff at a nephrology clinic stress the fact that they work with patients who need care several times a week, most likely for the rest of their lives. This poses particular challenges to the ways in which they interact with patients (see also Brüggemann \& Persson, 2016; Wijma et al., 2016; Zbikowski, 2014). In the same way, what is considered abusive also varies between health care systems, and changes over time (d'Oliveira et al., 2002; Jewkes et al., 1998). At the palliative care clinic in Sweden where the current project was conducted, providing care in the home and being in close contact with patients' relatives gave rise to specific challenges that staff navigated. 
The current study has shown how efforts to prevent or deal with situations perceived as abusive to patients are part of the everyday work of health professionals. Group discussions early on in the project presented a somewhat scattered image of what abuse can be and what responsibilities the professionals considered that they had. A different image surfaced during the forum play workshops. These allowed the professionals to collectively talk about and enact situations of abuse as a rather common phenomenon affecting large parts of their work, not the least in the mundane and largely invisible areas of it. Simple procedures such as providing an injection or changing a bandage were raised during the workshops, underlining the risk of abusive situations arising in situations so mundane that staff may not even consider them to be a challenge. This is one of the major contributions of the workshops: abuse is framed as an everyday concern rather than rare instances of intentional harm. Forum play allowed them to talk about and make visible all the ways in which they carried out navigation work in order to prevent and manage situations of abuse. Further ethnographic studies are needed to analyze how efforts to deal with potentially abusive situations are enacted in everyday clinical work.

The concept of navigation work may appear to be rather common sense - certainly professionals navigate through their everyday work in order to solve problems and get things done as smoothly as possible. What the present study shows, however, is the particular kind of work that professionals do in order to navigate various situations related to potential abuse. Using navigation work as a concept elicits both what the professionals discussed and enacted in forum play scenes - what they do - and how they learned from each other - what they could do better. Navigation work, then, is inherent to care practices and part of care professionals' everyday work, but it also signifies the professionals' reflections on how to develop their care. As an analytical concept it therefore captures and makes visible a particular strand of individual and collective tinkering with material and relational dimensions to care practices (Mol et al., 2015), as well as a contextual reflexivity (Pols, 2006) through individual and collective articulations and enactments of how work against abuse can be improved. Tinkering is inherently reflexive, but navigation work emphasizes how this reflexivity can be analyzed and developed, not merely by telling stories, as Pols (2006) suggests, but through enactment and 
practice. Forum play visualized and enabled a particular kind of navigation work. Various forms of methods from the medical humanities and arts (Shapiro, Coulehan, Wear, \& Montello, 2009) will enable different ways of exploring navigation work, informing care practices in different ways.

In previous intervention projects using forum play, the reflections made by professionals in individual interviews revealed that the intervention had increased awareness and stimulated a stronger sense of responsibility to act against abuse (Brüggemann \& Persson, 2016; Swahnberg \& Wijma, 2012; Swahnberg et al., 2010). The current study, rather, contributes with an interactive and ethnographic approach, showing how the topic of abuse was engaged with in a collective learning practice. The study also suggests that the understanding that forum play enables, in which professionals are compelled to engage with abuse as part of everyday practice, facilitates constructive discussions and a collective approach. If the process ends there, however, professionals may easily find themselves overwhelmed by the challenge of dealing with all the everyday situations that may be experienced as abuse. In these cases, we suggest that the concept of navigation work provides a perspective and a vocabulary that could help professionals to develop their understanding of what abuse in health care is, and how they, individually and collectively, can work to prevent it. In addition, it elicits areas where abuse seems inevitable, where care landscapes become increasingly complex, where collective negotiations are destructive, or where tensions need to be resolved within severe time constraints. 


\section{Acknowledgements}

We would like to thank all the staff at the palliative care clinic for their collaboration in this project. We also thank Agneta Josephson, drama instructor, for her professional and respectful way of organizing forum play workshops. We are grateful to the anonymous reviewers for their generous feedback and insightful comments.

\section{Funding}

This work was financed by the Swedish Research Council (grant number 2014-2749). The funding body had no role in the study or the writing of the article. 


\section{References}

Boal, A. (2000). Theatre of the Oppressed. London: Pluto Press.

Braun, V., \& Clarke, V. (2006). Using thematic analysis in psychology. Qualitative Research in Psychology, 3(2), 77-101.

Brüggemann, A.J., Forsberg, C., Colnerud, G., Wijma, B., \& Thornberg, R. (2018). Bystander passivity in health care and school settings: Moral disengagement, moral distress, and opportunities for moral education. Journal of Moral Education, DOI: 10.1080/03057240.2018.1471391.

Brüggemann, A.J., \& Persson, A. (2016). Using forum play to prevent abuse in health care organizations: A qualitative study exploring potentials and limitations for learning. Education for Health, 29(3), 217-222.

Brüggemann, A.J., \& Swahnberg, K. (2013). What contributes to abuse in health care? A grounded theory of female patients' stories. International Journal of Nursing Studies, 50(3), 404-412.

Brüggemann, A.J., Wijma, B., \& Swahnberg, K. (2012). Abuse in health care: A concept analysis. Scandinavian Journal of Caring Sciences, 26(1), 123-132.

Coyle, J. (1999). Exploring the meaning of 'dissatisfaction' with health care: The importance of 'personal identity threat'. Sociology of Health \& IIIness, 21(1), 95-123.

Crawford, G. B., \& Price, S. D. (2003). Team working: palliative care as a model of interdisciplinary practice. Medical Journal of Australia, 179(6), S32.

Cussins, C. (1996). Ontological choreography: Agency through objectification in infertility clinics. Social Studies of Science, 26(3), 575-610.

Disch, E., \& Avery, N. (2001). Sex in the consulting room, the examining room, and the sacristy: Survivors of sexual abuse by professionals. American Journal of Orthopsychiatry, 71(2), 204217.

d'Oliveira, A. F. P. L., Diniz, S. G., \& Schraiber, L. B. (2002). Violence against women in health-care institutions: An emerging problem. Lancet, 359, 1681-1685. 
Driessen, A. (2018). Sociomaterial Will-Work: Aligning Daily Wanting in Dutch Dementia Care. In J. Boldt \& F. Krause (Eds.), Care in Healthcare: Reflections on Theory and Practice (pp. 111-133). London and New York: Palgrave Macmillan.

Fürst, C. J. (2000). Perspectives on palliative care: Sweden. Supportive Care in Cancer, 8(6), 441-443.

Goffman, E. (1959). The presentation of self in everyday life. New York: Doubleday.

Halldorsdottir, S. (1996). Caring and uncaring encounters in nursing and health care: Developing a theory. Linköping, Sweden: Linköping University.

Jewkes, R., Abrahams, N., \& Mvo, Z. (1998). Why do nurses abuse patients? Reflections from South African obstetric services. Social Science \& Medicine, 47(11), 1781-1795.

Josephson, A. (2011). Praktisk kunskap i att förhindra kränkningar - Rapport om dramapedagogiskt arbete med vårdpersonal [Practical knowledge in counteracting abuse in health care. Report on drama pedagogic work among health care staff] (Vol. 8). Gender and Medicine report series, Linköping, Sweden: Linköping University.

Lin, Y.-P., Watson, R., \& Tsai, Y.-F. (2013). Dignity in care in the clinical setting: a narrative review. Nursing Ethics, 20(2), 168-177.

Lin, Y. -P., \& Tsai, Y. -F. (2011). Maintaining patients' dignity during clinical care: a qualitative interview study. Journal of Advanced Nursing, 67(2), 340-348.

Mol, A. (2008). The logic of care: Health and the problem of patient choice. London, UK: Routledge.

Mol, A., Moser, I., \& Pols, J. (Eds.). (2015). Care in practice: On tinkering in clinics, homes and farms. Bielefeld, Germany: Transcript.

Österlind, E. (2011). Forum play: a Swedish mixture for consciousness and change. In S. Schonmann (Ed.), Key Concepts in Theatre/Drama Education (pp. 247-251). Rotterdam, The Netherlands: Sense.

Pols, J. (2006). Accounting and washing: Good care in long-term psychiatry. Science, Technology, \& Human Values, 31(4), 409-430. 
Shapiro, J., Coulehan, J., Wear, D., \& Montello, M. (2009). Medical humanities and their discontents: definitions, critiques, and implications. Academic Medicine, 84(2), 192-198.

Star, S. L., \& Strauss, A. (1999). Layers of silence, arenas of voice: The ecology of visible and invisible work. Computer supported cooperative work (CSCW), 8(1-2), 9-30.

Swahnberg, K., Thapar-Bjorkert, S., \& Bertero, C. (2007). Nullified: Women's perceptions of being abused in health care. Journal of Psychosomatic Obstetrics \& Gynecology, 28(3), 161-167.

Swahnberg, K., \& Wijma, B. (2011). Staff's awareness of abuse in health care varies according to context and possibilities to act. Journal of Psychosomatic Obstetrics \& Gynecology, 32(2), 6571.

Swahnberg, K., \& Wijma, B. (2012). Staff's perception of abuse in healthcare: A Swedish qualitative study. BMJ Open, 2:e001111. doi:10.1136/bmjopen-2012-001111

Swahnberg, K., Wijma, B., Hearn, J., Thapar-Björkert, S., \& Berterö, C. (2009). Mentally pinioned: Men's perceptions of being abused in health care. International Journal of Men's Health, 8(1), 60-71.

Swahnberg, K., Zbikowski, A., \& Wijma, B. (2010). Ethical lapses: Staff's perception of abuse in health care. Journal of Psychosomatic Obstetrics \& Gynecology, 31(3), 123-129.

Svensson, L., Ellström, P.-E., \& Brulin, G. (2007). Introduction-On interactive research. International Journal of Action Research, 3(3), 233-249.

Timmermans, S., \& Almeling, R. (2009). Objectification, standardization, and commodification in health care: a conceptual readjustment. Social Science \& Medicine, 69(1), 21-27.

Wellbery, C., \& Chan, M. (2014). White coat, patient gown. Medical humanities, 40, 90-96.

Wenger, E. (1998). Communities of practice: Learning, meaning, and identity. New York, NY: Cambridge University Press.

Wijma, B., Zbikowski, A., \& Brüggemann, A. J. (2016). Silence, shame and abuse in health care: Theoretical development on basis of an intervention project among staff. BMC medical education, 16,75 . 
Vogel, E. (2016). Clinical specificities in obesity care: The transformations and dissolution of 'will' and 'drives'. Health Care Analysis, 24(4), 321-337.

Zbikowski, A. (2014). Counteracting Abuse in Health Care from a Staff Perspective (Vol. 1406). Linköping, Sweden: Linköping University.

Zuiderent-Jerak, T. (2015). Situated Intervention: Sociological Experiments in Health Care. Cambridge, MA: MIT Press. 